J. Clin. Chem. Clin. Biochem.

Vol. 26, 1988, pp. 667-671

(C) 1988 Walter de Gruyter \& Co. Berlin $\cdot$ New York

\title{
Diagnostic Validity of Multivariate Combinations of Biochemical Analytes as Markers for Rejection and Infection in the Follow-Up of Patients with Heart Transplants
}

\author{
By W. G. E. Hölzel
}

Institut für Pathologische und Klinische Biochemie, Humboldt-Universität Berlin, Charité, Berlin (GDR)

\author{
M. Havel, A. Laczkovics and M. M. Müller \\ II. Chirurgische Universitätsklinik, AKH, Wien (Austria)
}

(Received August 8, 1987//March 25/July 29, 1988)

Summary: The diagnostic validity of multivariate combinations of $\alpha_{1}$-antitrypsin, $\alpha_{2}$-macroglobulin, C-reactive protein, complement $\mathrm{C} 3$, complement $\mathrm{C} 4$, neopterin in serum, and neopterin in urine as markers for acute cardiac allograft rejection and for differential diagnosis of rejection and infections was investigated in the follow-up of 37 patients with heart transplants. Rejection was diagnosed by endomyocardial biopsy. Infections were classified as 'no infection', 'viral infection', and 'bacterial, fungal or mixed infections'. Although there are significant differences between the mean levels of analytes, multivariate discriminant analysis does not provide an adequate discrimination of rejection and infection states. In separate rejection diagnosis, multivariate combinations of analytes cannot replace endomyocardial biopsy. However, a multivariate combination of $\alpha_{1}$-antitrypsin, $\alpha_{2}$-macroglobulin, C-reactive protein, C3, C4 in serum, and neopterin in urine can be used as a screening procedure to reduce the number of endomyocardial biopsies.

\section{Introduction}

Heart transplantation hạ become an accepted method in the treatment of patients with end-stage heart diseases (1). Despite significant improvements in the clinical management of heart transplant recipients by immunosupporession with cyclosporin $\mathrm{A}$, rejection still remains a major problem. Rejection needs special treatment, the success of which depends on early recognition. Although some non-invasive techniques have been suggested (e.g. 1.c. $(2-5)$ ), no methods exist for a reliable early diagnosis of rejection episodes. A reliable diagnosis can be made only by percutaneous transvenous right ventricular endomyocardial biopsy $(6-8)$. This is an invasive technique and it carries the risk of complications (9). A noninvasive method which would adequately replace or at least reduce the number of endomyocardial biopsies would be very useful.
In an early study we investigated the diagnostic validity of some biochemical analytes which were involved in the rejection process (10). We found that $\alpha_{1}$-antiproteinase ( $\alpha_{1}$-antitrypsin), C-reactive protein, $\alpha_{2}$-macroglobulin, complement components $\mathrm{C} 3$ and $\mathrm{C} 4$ in serum, and neopterin in urine have some discriminatory power in rejection diagnosis, but in all cases it was too weak for a reliable exclusion or confirmation of rejection in need of treatment. In practice, the diagnosis of rejection is complicated by bacterial, viral or fungal infections, which are frequent in patients under immunosuppressive treatment, and which additionally influence the analytes. In this study we investigated whether multivariate combinations of analytes might allow a reliable detection of cardiac allograft rejection and its discrimination from infections. 


\section{Materials and Methods}

Patients

Our group consisted of 37 patients ( 35 men and 2 women), age $10-55$ years in the follow-up after orthotopic heart transplantation carried out at the 2nd Department of Surgery, University of Vienna. Routine immunosuppression consisted of cyclosporin A and azathioprine according to the Standford scheme (11). All patients had normal renal functions. Three patients which developed renal failure after transplantation in the course of treatment were not included in our study.

\section{Rejection state}

The rejection state of the patients was diagnosed by endomyocardial biopsy. Endomyocardial biopsies were performed according to Caves et al. $(6,7)$ and judged according to Billingham (8). Biopsies were taken weekly during the 1 st month after operation, fortnightly during the 2 nd month, monthly up to the 6 th month, and thereafter once per year. Biopsies were also taken if there was any clinical suspicion of rejection. We included only biopsies taken later than 3 weeks after transplantation to avoid the influence of primary healing on the analytes. We excluded control biopsies taken during the treatment of an acute rejection to exclude the influence of therapy (high dosage of methylprednisolone).

\section{Infection state}

The diagnosis of infections was based on clinical symptoms and repeated bacteriological and serological tests such as blood and urine cultures, IgM- and IgG-titres, complement binding reactions, and virus isolations.

\section{Analytical methods}

The serum proteins, $\alpha_{1}$-antitrypsin, $\alpha_{2}$-macroglobulin, C3, and C4, were determined nephelometrically (Behring $\mathrm{N}$-reagent, Behring Laser Nephelometer, Behringwerke AG, Marburg/ FRG). C-reactive protein (CRP) as also analysed nephelometrically with NA latex-CRP Reagent (Behringwerke AG). Neopterin in serum and urine were determined by a radioimmunoassay (Henning, Berlin).

\section{Statistical methods}

The original values of the analytes were not normally distributed, while the transformed values $(\log x)$ are approximately normally distributed. Because analysis of variance and discriminant analysis require approximately normally distributed variables, we used these transformed values for calculations. For comparison of the mean values of both rejection states $A$ and B in the infection groups we used Student's t-test. For comparison of the mean values of the three infection states in the rejection groups we used variance analyses and Scheffe's multiple-comparison procedure. To check the diagnostic validity of a multivariate approach for differentiating between the two rejection states in the infection groups, as well as for differentiating between infection and rejection states, we performed discriminant analyses using the SAS-system procedure Discrim (12). The observations were classified into the diagnostic group with the highest posterior probability. The prior probabilities were assumed to be equal.

\section{Criteria of diagnostic validity}

The criteria commonly used to judge the diagnostic validity of a biochemical test are diagnostic sensitivity, diagnostic specificity, and predictive values of the positive and the negative tests
$(13,14)$. These criteria are valid for a two class problem. Because rejections are combined with infection states, there were more than two diagnostic classes in our study. To differentiate rejection and infection states simultaneously, it was convenient to define diagnostic sensitivities only. If an individual has the diagnostic state $\mathrm{Dj}$, the probability of obtaining the test classification $T D j$ is $P(T D j / D j)$. This was estimated by dividing the number of individuals in state $\mathrm{Dj}$ which have a test classification TDj by the number of all tests in this group. A predictive value $P V_{D j / T D i}$ is the probability $P(D j / T D i)$ that an individual is in the diagnostic state $\mathrm{Dj}$, if the test classification is TDi. There are many predictive values. We have calculated the predictive value $P V_{\mathrm{Dj} / \mathrm{TD} i}$ only, representing the probability that the test classification and diagnostic state agree. These probabilities were estimated by dividing the number of test classifications TDj of individuals with the diagnostic state $D_{j}$ by the number of all test classifications TDj. Predictive values depend on the prior probabilities $\mathrm{P}(\mathrm{Dj})$ of the diagnostic state $\mathrm{Dj}$. If the prior probabilities in a study do not reflect the real clinical prior probabilities, the real prior probabilities must be inserted into the calculations. In our study the prior probabilities of $\mathrm{Di}$ reflect the clinical situation, so that no additional calculations were necessary.

\section{Results}

We included 236 endomyocardial biopsies taken from 37 patients in our study. The histological findings were $27 \times$ grade $0,74 \times$ grade $0.5,79 \times$ grade 1.0 , $22 \times$ grade $1.5,31 \times$ grade 2.0 , and $2 \times$ grade 2.5 . Mild rejections are common and do not need special treatment. Therefore, we established two rejection groups. Rejection group A contains all observations with no histological signs of rejections (histological grade 0) and observations with mild rejections (histological grade 0.5 and 1.0) which do not need special treatment. Group B contains all observations with moderate or severe rejection (histological grades 1.5, 2.0 and 2.5) which need special treatment. Nineteen patients had one episode, 8 patients had two episodes, and one patient had three episodes of acute rejections (histological grade $>1.0$ ). Nine patients never had any acute rejection. The fraction of rejection states $B$ was 0.23 .

For the infection state we established three groups. Group 1 contains all observations without detectable infection, group 2 contains all observations with viral infections, and group 3 contains all observations with bacterial, fungal, or mixed infections. The rate of viral infection was 0.39 , often without clinical symptoms. Bacterial, fungal or mixed infections were not so frequent, the rate being 0.13 . The frequency of rejection states $B$ did not differ between the three infection states (B1 0.23, B2 0.25, B3 0.20). The classification of the observations into the six diagnostic classes according to the results of endomyocardial biopsies, bacteriological, serological, viral tests, and clinical symptoms is given in table 1 . 
Tab. 1. Classification criteria and number of observations in the diagnostic groups investigated

\begin{tabular}{|c|c|c|c|c|}
\hline & \multicolumn{4}{|c|}{ Infection state of the patients } \\
\hline & $\begin{array}{l}\text { No } \\
\text { infec- } \\
\text { tions }\end{array}$ & $\begin{array}{l}\text { Viral } \\
\text { infec- } \\
\text { tions }\end{array}$ & $\begin{array}{l}\text { Bacterial, } \\
\text { fungal } \\
\text { or mixed } \\
\text { infections }\end{array}$ & Total \\
\hline $\begin{array}{l}\text { No rejection, } \\
\text { in need } \\
\text { of treatment }\end{array}$ & $\begin{array}{l}\mathbf{A 1} \\
\mathrm{n}=87\end{array}$ & $\begin{array}{l}\mathrm{A} 2 \\
\mathrm{n}=70\end{array}$ & $\begin{array}{l}\text { A3 } \\
n=25\end{array}$ & $\begin{array}{l}A 1-3 \\
n=182\end{array}$ \\
\hline $\begin{array}{l}\text { Rejection, } \\
\text { in need } \\
\text { of treatment }\end{array}$ & $\begin{array}{l}\mathrm{B} 1 \\
\mathrm{n}=25\end{array}$ & $\begin{array}{l}\text { B2 } \\
n=23\end{array}$ & $\begin{array}{l}\text { B3 } \\
\mathrm{n}=6\end{array}$ & $\begin{array}{l}\mathrm{B} 1-3 \\
\mathrm{n}=54\end{array}$ \\
\hline Total & $\mathrm{n}=112$ & $\mathrm{n}=93$ & $\mathrm{n}=31$ & $\mathbf{n}=236$ \\
\hline
\end{tabular}

Statistically significant differences between the mean values of the diagnostic classes are a sign of discriminatory power of the analytes. The analytes, $\alpha_{1}$-antitrypsin, $\alpha_{2}$-macroglobulin, C-reactive protein, C3, C4 in serum and neopterin in urine, had some discriminatory power for the differentiation of the two rejection states, but on different scales. $\alpha_{2}$-Macroglobulin and $\mathrm{C} 3$ showed discriminatory differences only in the group 'viral infections', while neopterin in urine showed discriminatory differences in the group 'no infection'. There were no significant differences in the the group 'bacterial, fungal or mixed infections', but 6 observations in the rejection group B of this infection state were too small for an adequate statistical analysis. All analytes investigated had some discriminatory power for the differentiation of the three infection states. Between the states 'no infection' and 'viral infection', only neopterin in urine and C3 showed significant differences, whereas the mean concentrations of all analytes investigated were significantly different between the states 'no infection' and 'bacterial, viral and mixed infections', as well as between the states 'viral infection' and 'bacterial, fungal or mixed infection'. The exception was $\alpha_{2}$-macroglobulin, which differed only between 'viral infections' and 'bacterial, fungal or mixed infections'. Despite significant differences between the mean concentrations of the analytes, the distributions overlapped considerably, so that a discrimination between the diagnostic classes was impossible if each analyte is viewed separately (10). In a first step we investigated whether there was any chance of discriminating all six diagnostic classes by a multivariate combination of analytes in a discriminant analysis. Because all analytes investigated had some discriminatory power in at least one discriminating problem, all were used as variables. Exclusion of one or more analytes resulted in poorer discrimination. The diagnostic sen-
Tab. 2. Diagnostic sensitivities and predictive values of the simultaneous differentiation of rejection and infection states of patients with heart transplants by mulitivariate combination of $\alpha_{1}$-antitrypsin, $\alpha_{2}$-macroglobulin, C-reactive protein, C3, C4, and neopterin in serum and neopterin in urine.

\begin{tabular}{lll}
\hline Diagnostic state & $\begin{array}{l}\text { Diagnostic } \\
\text { sensitivity } \\
\text { P(TDj/Dj) }\end{array}$ & $\begin{array}{l}\text { Predictive } \\
\text { value } \\
\mathrm{P}(\mathrm{Dj} / \mathrm{TDj})\end{array}$ \\
\hline $\begin{array}{l}\text { No infection, no rejection, } \\
\text { in need of treatment }\end{array}$ & 0.40 & 0.68 \\
$\begin{array}{l}\text { Viral infection, no rejection, } \\
\text { in need of treatment }\end{array}$ & 0.49 & 0.57 \\
$\begin{array}{l}\text { Bacterial, fungal or } \\
\text { mixed infection, no reaction, } \\
\text { in need of treatment }\end{array}$ & 0.30 & 0.33 \\
$\begin{array}{l}\text { No infection, rejection, } \\
\text { in need of treatment }\end{array}$ & 0.50 & 0.32 \\
$\begin{array}{l}\text { Viral infection, rejection, } \\
\text { in need of treatment }\end{array}$ & 0.32 & 0.26 \\
$\begin{array}{l}\text { Bacterial, fungal or } \\
\text { mixed infection, rejection, } \\
\text { in need of treatment }\end{array}$ & 0.33 & 0.06 \\
\hline
\end{tabular}

sitivities $P(T D j / D j)$ and the predictive values $P(D j /$ TDj) derived from the classification based on this discriminant function are given in table 2.

Because the discrimination by this approach was not sufficient and the diagnosis of the infection states can be made by bacteriological, serological and virological tests, we studied the power of multivariate combinations of analytes for discriminating the rejection states separately. We used three different discriminant functions. The first function (DF-1) was derived by discriminant analysis, including all observations classified into the two rejection states $\mathrm{A}$ and $\mathrm{B}$, neglecting the infection state of the patients. We got the best discrimination by the combination of $\alpha_{1}$-antitrypsin, $\alpha_{2}$-macroglobulin, C-reactive protein (CRP), C3, C4 in serum, and neopterin in urine. An observation was classified in rejection class $A$ if $X_{A}>X_{B}$ and in rejection class $B$ if $X_{B}>X_{A} \cdot X_{A}$ and $X_{B}$ were calculated as follows:

$\mathrm{X}_{\mathrm{A}}=-161.40-16.96 \log \left(\alpha_{1}\right.$-antitrypsin $)+28.52$ $\log \left(\alpha_{2}\right.$-macroglobulin $)-9.92 \log (C R P)-66.02 \log$ (C3) $+124.50 \log (\mathrm{C} 4)+20.78 \log$ (neopterin in urine)

$\mathrm{X}_{\mathrm{B}}=-169.80-13.74 \log \left(\alpha_{1}\right.$-antitrypsin $)+27.42$ $\log \left(\alpha_{2}\right.$-macroglobulin $)-9.26 \log (C R P)-67.75 \log$ (C3) $+127.87 \log (\mathrm{C} 4)+20.66 \log$ (neopterin in urine) 
Tab. 3. Diagnostic sensitivities and predictive values of the discrimination between the rejection states $A$ (no rejection, in need of treatment) and B (rejection, in need of treatment)

\begin{tabular}{llllll}
\hline $\begin{array}{l}\text { Infection } \\
\text { group }\end{array}$ & $\begin{array}{l}\text { Discriminant } \\
\text { function } \\
\text { DF }\end{array}$ & $\begin{array}{l}\text { Diagnostic } \\
\text { sensitivity } \\
\text { P(TA/A) }\end{array}$ & $\begin{array}{l}\text { Diagnostic } \\
\text { sensitivity } \\
\text { P(TB/B) }\end{array}$ & $\begin{array}{l}\text { Predictive } \\
\text { value } \\
\text { P(A/TA) }\end{array}$ & $\begin{array}{l}\text { Predictive } \\
\text { value } \\
\text { P(B/TB) }\end{array}$ \\
\hline Total & DF-1 & 0.72 & 0.78 & 0.92 & 0.1 \\
No infection & DF-1 & 0.74 & 0.74 & 0.44 & 0.44 \\
Viral infection & DF-1 & 0.85 & 0.85 & 0.94 & 0.67 \\
No infection & DF-2 & 0.80 & 0.76 & 0.92 & 0.53 \\
Viral infection & DF-3 & 0.84 & 0.75 & 0.93 & 0.60 \\
\hline
\end{tabular}

DF-1: $\alpha_{1}$-antitrypsin, $\alpha_{2}$-macroglobulin, C-reactive protein, C3, C4 in serum, neopterin in urine

DF-2: $\alpha_{1}$-antitrypsin, C-reactive protein, $C 4$, neopterin in urine

DF-3: $\alpha_{1}$, antitrypsin, $\alpha_{2}$-macroglobulin, C-reactive protein, C3, C4

We studied the discriminatory power of this discriminant function for the infection states 'no infection' and 'viral infections' using the two groups as test classes. Additionally, we studied whether the discriminatory power of analytes could be improved by calculating a specific discriminant function for the states 'no infections' and 'viral infections'. This is of practical relevance for cases where the infection state of the patients is known. The discriminant function DF2 was derived using observations of the state 'no infection' for discriminant analysis separately, and the discriminant function DF-3 using observations of the state 'viral infections' only. When computing the discriminant functions, analytes were taken which have disciminatory power for the specific problem. These are $\alpha_{1}$-antitrypsin, $\mathrm{C}$-reative protein, $\mathrm{C} 4$, and neopterin in urine for DF-2, and $\alpha_{1}$-antitrypsin, $\alpha_{2}$-macroglobulin, C-reative protein, C3 and C4 for DF-3. Exclusion of analytes resulted in poorer discrimination, while the inclusion of additional analytes did not improve discrimination. Diagnostic sensitivities and predictive values derived from test classifications based on the three discriminant functions are given in table 3.

Endomyocardial biopsy, which is used as the reference method in establishing the rejection states A and B, has a random variation. The results depend on the pathologist examining the material. The pattern of rejection may not be uniform throughout the myocardium. Additionally, there is theoretically no clear cut-off point between rejections with a need for treatment and those without a need for treatment. Therefore, we studied the discriminatory power of the discriminant function DF-1 for observations with histological grades of rejection $0,0.5$ and 2.0, 2.5 separately. The predictive value of a test classification $\mathrm{A}$ for a rejection state histological grade lower than 2.0 was 0.96 . The predictive value of a test classification $\mathrm{B}$ for a rejection state higher than 0.5 was 0.88 .

\section{Discussion}

All analytes investigated are at least locally involved in rejection and infection processes. Both processes are accompanied by an activation of macrophagès which release the mediator interleukin-1. Interleukin-1 stimulates the production of acute phase proteins in liver, including $C$-reactive protein, $\alpha_{1}$-antitrypsin, and the complement factors C3 and C4. $\alpha_{1}$-Antitrypsin and $\alpha_{2}$-macroglobulin are proteinase inhibitors, and they are consumed by the inactivation of proteinases which are released in rejection and infection processes. $\mathrm{C} 3$ and $\mathrm{C} 4$ are consumed by complement activation. Interleukin-1 also activates T-cells (15). Activated Tcells secrete the lymphokine, $\gamma$-interferon, which stimulates the release of neopterin from macrophages $(16$, 17). There are differences in the production, the localization, the activation, and the consumption of analytes, depending on whether the patient is suffering rejection, viral infection, or bacterial or fungal infections; these differences should result in changes of the circulating concentrations of the analytes, which may provide a basis for the discrimination between rejection and infection states, using a multivariate combination of analytes. From a theoretical point of view an approach based on subject-specific reference ranges should be more efficient for the discrimination of the different rejection and infection states than an approach based on group reference ranges. But the estimation of a subject-specific reference range requires at least eight individual reference values, which must be taken during a stationary phase of the disease, and the consecutive observations must be spaced so that the values of the analytes are independent of each other $(18,19)$. In practice it is very difficult to get such a series of individual reference values. Variations frequently occur in the different rejection and infection states of the patients. We therefore chose approach based on group reference values. Because the number of heart recipients was limited, we included 
more than one observation per patient in the different diagnostic classes. From a statistical point of view this approach is not quite exact, due to the mixing of intra- and inter-individual variance components. From a practical point of view it can be accepted, because the number of individuals in each class exceeded the maximum number of observations per individual at least tenfold, so that a smaller intraindividual variance did not substantially influence the calculated group variance.

As expected theoretically, the six diagnustic classes showed different patterns, but the differences between the classes were too small for an adequate discrimination by discriminant analysis; the diagnostic sensitivities with a maximum of 0.50 and the predictive values with a maximum of 0.68 are too low to be of practical use. We cannot recommend the multivariate combination of analytes investigated in this study for the simultaneous discrimination between rejection and infection.

Infection can be diagnosed by specific tests. Therefore, the separate diagnosis of rejection is of practical importance. Neither the multivariate discriminant function derived without considering the different infection states of the patients, nor the specific multivariate discriminant functions for the infection states 'no infection' and 'viral infections' allowed a complete discrimination between the two states: 'no rejection in need of treatment' and 'rejection in need of treatment'. The highest diagnostic sensitivity was 0.85 and the lowest 0.74 . Therefore, the multivariate combination of analytes investigated in this study cannot replace the endomyocardial biopsy for diagnosing cardiac allograft rejection. But it can be useful as a screening procedure. The predictive values of the test classification 'rejection in need of treatment' are much too low (0.44 to 0.67$)$ to allow the confirmation of the diagnosis 'rejection in need of treatment'; but they are high enough to use such a test classification as an indication for an endomyocardial biopsy, especially if there are other symptoms of a possible rejection. The predictive values of the test classification 'no rejection in need of treatment' are high enough (0.91 to 0.94$)$ to allow the exclusion of a 'rejection in need of treatment', if there are no clinical symptoms of an acute cardiac allograft rejection. We suggest the use of the discriminant function DF-1. This function does not require any knowledge of the infection state of the patient and results in a good classification of the rejection states of patients without any infection and patients with viral infections. The discriminatory power of the discriminant function increases if intermediate states of rejection are excluded and only clear states of rejection are classified.

\section{References}

1. Copeland, J. G., Emercy, R. W., Levinson, M. M., Copeland, J., McAlbeer, M. J. \& Riley, J. E. (1985) Circulation 72 (suppl. II), 7-12.

2. Dawkins, K. D., Oldershaw, P. J., Billingham, M. E., Hunt, S. A., Oyer, P. E., Jamieson, S. W., Popp, R. L., Stinson, E. B. \& Shumway, N. E. (1984) J. Heart Transplantation 3, 286-292.

3. Reichenspurner, H., Ertel, W., Hammer, C., Lersch, C., Reichart, B., Uberfuhr, P., Welz, A., Reble, B., Kemkes, B. M. \& Gokel, M. (1984) Transplant Proc. 16, 1251-1254.

4. Warnecke, H., Schueler, S., Goetze, H. J., Matheis, G., Suethoff, U., Mueller, J., Tietze, U. \& Hetzer, R. (1986) Circulation 74 (suppl. III), 72-76.

5. Chandrasekaran, K., Bansal, R. C., Greenleaf, J. F., Hauck, H., Seward, J. R., Rajik, A. J. \& Bailey, L. L. (1987) J. Heart Transplantation $6,1-7$.

6. Caves; P. K., Stinson, E. R., Billingham, M. E., Rider, A. K. \& Shumway, N. E. (1973) J. Thorac Cardiovasc. Surg. 66,461 .

7. Caves, P. K., Stinson, E. B., Billingham, M. E., Rider, A. K. \& Shumway, N. E. (1975) Heart Lung 4, 69.

8. Billingham, M. E. (1981) Heart Transplant. 1, 25-30.

9. Sekiguchi, M. \& Take, M. (1980) World survey of catheter biopsy of the heart (Sekiguchi, M. \& Olsen, E. G. J., eds.) Cardiomyopathy. Clinical, pathological, and theoretical aspects. Baltimore: University Park Press, pp. 217-225.

10. Hölzel, W. G. E. \& Müller, M. M. (1988) Z. Med. Lab.diagnostik (in press).

11. Griffith, B. P., Hardesty, R. L., Bahnson, H. T. (1984) J. Thorac. Cardiovasc. 87, 35-42.

12. SAS User's Guide (1985): Statistics, Version 5 Edition. SAS Institute Inc., Cary, NC. 956 pp.

13. Galen, R. S. \& Gambino, S. R. (1975) Beyond Normality: The predictive value and efficiency of medical diagnosis. New York: Wiley J. and Sons.

14. Büttner, J. (1977) J. Clin. Chem. Clin. Biochem. 15, 1-12.

15. Farrar, W. L., Mizel, S. B. \& Farrar, J. J. (1980) J. Immunol. 124, $1371-1377$.

16. Margreiter, R., Fuchs, D., Hansen, A., Huber, Ch., Reibnegger, G., Spielberg, M. \& Wachter, H. (1983) Transplantation $36,650-653$.

17. Woloszczuk, W., Troppmair, J., Leiter, E., Flener, R., Schwarz, M., Kovarik, J., Pohanka, E., Margreiter, R. \& Huber, Ch. (1986) Transplantation 41, 716-719.

18. Harris, E. K. \& Yasaka, T. (1983) Clin. Chem. 29, 25-30.

19. Hölzel, W. (1987) Clin. Chem. 33, 670-673.

Prof. Dr. W. Hölzel

Institut für Pathologische und

Klinische Biochemie

Humboldt-Universität Bcrlin

Charité

Schumannstraße 20/21

DDR-1040 Berlin 
